\title{
INTELECTO AGENTE, FORMA FORMARUM, LIBERTAD. DE ARISTÓTELES A HEGEL, Y VUELTA A TOMÁS DE AQUINO
}

\author{
INTELLECT AGENT, FORMARUM FORM, FREEDOM. FROM ARISTOTLE \\ TO HEGEL, AND FORTH TO THOMAS AQUINAS
}

\author{
Javier Hernández-Pacheco ${ }^{1}$ \\ Universidad de Sevilla (España)
}

Recibido: 27-05-2014

Aceptado: 15-08-2014

Resumen: Que toda intelección tiene un momento de pasividad que liga el conocimiento a las condiciones de la experiencia sensible, es consecuencia del carácter finito de la subjetividad humana. Sin embargo, dicha intelección no se entiende sino desde una actividad incondicionada que antecede a todo conocimiento y de la que resulta la forma de la inteligibilidad como reflexión del sujeto en sí desde la exterioridad sensible. La libertad se muestra así como la última condición de posibilidad de todo co-nocimiento. Esta esencial correlación de libertad y conocimiento intelectual constituye un hilo conductor que emerge en los grandes clásicos del pensamiento filosófico. Intelecto agente aristotélico y apercepción trascendental kantiana, tienen esencial-mente que ver.

Palabras-clave: Intelecto agente, intelecto paciente, libertad.

\begin{abstract}
Thinking has always a receptive dimension which links knowledge to the con-ditions of sensual experience. This is a consequence of the essential finitude of human subjectivity. Nevertheless, understanding intellection presupposes an unconditioned activity which antecedes all knowledge, and from which results the form of any intelligibility as reflections of the subject in itself back from that sensual exteriority. Freedom is then the last condition of possibility of knowledge in general. This essential correlation of liberty and intellectual knowledge represents a driving force that continually emerges through the main line of the classics of philosophical thought. Aristotelian active intellect and Kantian transcendental apperception are di-verse formulation of the same.
\end{abstract}

Key-words: Agent Intellect, Passive Intellect, Freedom.

[1] (jpacheco@us.es) Catedrático de Filosofia de la Universidad de Sevilla. Visiting Scholar en la Universidad de Columbia, Nueva York (1985-86), en el MIT, Cambridge, Massachussetts y en la Northwestern University, Evanston, Illinois (1992) y en la Universidad de Oxford, Reino Unido (2005-2006). 


\section{La identidad actual del entendimiento}

Aceptemos de entrada que Aristóteles gana su primer impulso filosófico en la crítica de su maestro. No son pocos los autores que han querido, como se expresa Hegel, rescatar para la tierra los tesoros dilapidados en el cielo²; recuperar en definitiva la dignidad ontológica de este mundo sublunar, o histórico, o sensible. Este pensamiento, por así decir «reivindicativo», se entiende como una crítica de la meta-física, del sobre-naturalismo platónico; y supone ciertamente la revisión de la doctrina académica del horismós: de ese horizonte separador que sitúa el ontos on, lo ente del ente, más allá de su inmediatez física.

Según esto, bien parece que el patrón filosófico de todo este pensamiento revolucionario sería Aristóteles, al afirmar que ese núcleo ontológico, el destilado metafísico que da cuenta como principio de todo lo demás, la ousía o capital ontológico de las cosas, no es un ente trans-mundano, genéricamente determinado más allá de lo inmediatamente accesible en la experiencia, sino más bien eso que inmediatamente se nos ofrece en esa nuestra experiencia del mundo. Lo que es ( $t i$ esti), como aquello que define la cosa, es «esto» que es, este algo (tóde ti) que ostensiblemente podemos señalar en su presencia sensible $^{3}$. La proté ousía, la substancia primera de las cosas, es lo que en ellas se nos muestra como naturaleza propia, como physis. El individuo concreto, en su variopinta diversidad, en su particularidad -in rerum natura, dirán los escolásticos-, es lo que "verdaderamente» existe.

Por ello, es también un lugar común en la historia de la filosofía, ahora desde el punto de vista gnoseológico, que esto supone, también frente a Platón, una revalorización del conocimiento sensible. El camino hacia las definiciones que buscara Sócrates, no implica, por así decir, desembragar la mente de esa experiencia sensible para emprender un proceso de interiorización reflexiva ("noli foras ira, in teipsum redi...", como lo expresa San Agustín ${ }^{4}$ ) hacia esencias inteligibles que el alma encuentra como innatas en sí misma. Antes bien, para Aristóteles, el acceso a las determinaciones principiales de las cosas está esencialmente ligado a dicha experiencia sensible. Como no podía ser menos dado el carácter particular e individual, corpóreo incluso, de esas cosas. De ahí la idea de que, en lo que al conocimiento se refiere, el alma es «sicut tabula rasa»" , como esas tablas enceradas y recién planchadas, sin nada escrito en ellas, con que los niños iban cada mañana a la escuela, a aprender escribiendo cosas nuevas.

[2] Cf. Die Positivität der christlichen Religion, Hegels Werke, Ed. Suhrkamp, Frankfurt a. M. 1971, I, p. 209.

[3] Cf. Met. VII, 3, 1029 a 28 ss.

[4] De vera religione, 72.

[5] De anima, III, 4, 429 b 30 s.: «Lo inteligible ha de estar en él del mismo modo que en una tablilla en la que nada está actualmente escrito: esto es lo que sucede con el intelecto». Sigo en general la traducción de Tomás Calvo.

THÉMATA. Revista de Filosofía, $\mathrm{N}^{\circ} 50$ julio-diciembre (2014) pp.: 69-94 doi: 10.12795/themata.2014.i50.03 
Hasta aquí se trata de tópicos -en el mejor sentido- del pensamiento filosófico. Sólo que estas cuestiones adquirieron especial relevancia allá por el siglo XIV, cuando en torno a la cuestión de qué significaban propiamente las palabras, Guillermo de Okham, radicaliza este planteamiento aristotélico, con inmensas consecuencias en el posterior desarrollo de la filosofía moderna. La culpa, si se permite la expresión, la volvieron a tener los platónicos, que en su teoría de la predicación lingüística insistían en que, puesto que hay palabras que se pueden decir de muchos individuos, que son pues "universales», esas palabras tenían que significar algo "común» a esa multiplicidad individual, algo igualmente genérico y universal, que no podía ser sino las mismas esencias platónicas, abstractas, que quiere decir, separadas de la realidad individual y sensible. Frente a ellos Ockham señala que todas las palabras adquieren su significación, no por sí mismas, sino en el uso predicativo en que el lenguaje se refiere siempre a sujetos concretos. El lenguaje no dice algo, sino que dice algo de algo (ti kata tinós, dice Aristóteles); de modo que este último algo al que nos referimos cuando decimos algo, es el origen individual, empírico y sensiblemente accesible de toda significación. Dicho de otra forma: la significación de las palabras, en lo que tienen de universal, resulta de una construcción lingüística. Técnicamente expresado: toda suppositio communis se resuelve en último término en una suppositio personalis, más concretamente, en lo que Ockham denomina una suppositio personalis confusa, en la que los términos se refieren de modo borroso a una multiplicidad de individuos. Dicho con cierta brutalidad: toda significación abstracta no tiene más consistencia que el flatus vocis, que el ruido del aire ${ }^{7}$.

La cuestión es ahora si Aristóteles hubiese llevado su crítica del platonismo y su reivindicación del carácter empírico del conocimiento a estos extremos nominalistas. Y parece que no es así. Más bien entiende que el conocimiento verdadero se expresa lógicamente, en un discurso comunicable y por medio de términos significativos, capaces de expresar, efectivamente, lo que las cosas son. Dicho de otra forma: el discurso verdadero no es una simple descripción de hechos empíricos, sino expresión de significaciones lógicas, no meramente lingüísticas, en las que lo múltiple se expresa como uno, en

[6] Summa Logicae, I, cap. 70, 44-50: «Suppositio personalis confusa tantum est quando terminus communis supponit personaliter et non contingit descendere ad singularia per disiunctivam, nulla variatione facta a parte alterius extremi, sed per propositionem de disiuncto predicato, et contingit eam inferri ex quocumque singulari. Verbi gratia in ista 'omnis homo est animal', li animal supponit confuse tantum, quia non contingit descendere sub animali ad sua contenta per disiunctivam».

[7] Como es sabido, la expresión procede según Anselmo de Canterbury de Roscelino: «[...] Illi utique dialectici, qui non nisi flatum vocis putant universalis esse substantias, et qui colorem non aliud queunt intellegere quam corpus, nec sapientiam hominis aliud quam animam, prorsus a spiritualium quaestionum disputatione sunt exsufflandi» (De Incarnatione Verbi, Opera Omnia, I, p. 285. Ed. F. S. Schmitt, 1938).

THÉMATA. Revista de Filosofía, $\mathrm{N}^{\circ} 50$ julio-diciembre (2014) pp.: 69-94 doi: 10.12795/themata.2014.i50.03 
un sentido ontó-lógico compartido. De ahí que el objeto del conocimiento no sean los hechos sino su sentido. Y de ahí que, por mucho que el conocimiento comience en los sentidos y en el contacto físico con la realidad individual, en absoluto termina ahí, sino allí donde ese conocimiento expresa la forma de las cosas, como aquello que las define lógicamente desde los principios que determinan su naturaleza. Conocer los pájaros, saber de pájaros, no consiste en ver muchos pájaros, sino en «entender» de pájaros, lo que ocurre allí donde se nos abre la significación de este tipo de esencias, a saber, desde los principios que determinan su forma de ser, de actuar, de vivir.

Resulta entonces que en su crítica de Platón, Aristóteles no hace sino reformular la teoría del maestro. Porque también para él la verdad del conocimiento está en la manifestación de las cosas a la luz del entendimiento. Porque eso es lo que Platón denominaba una idea. Sólo que la idea no es "una» cosa en sí misma perfecta y lógicamente transparente, de la que las «muchas» cosas participan o que imperfectamente «imitan». Más bien entiende Aristóteles más radicalmente al mismo Platón; pues éste decía que la idea era la cosa "misma», pero la situaba luego «fuera», más allá del citado horismós; mientras que el Estagirita dice que esa mismidad ónto-lógica tiene que estar "dentro", como aquello desde lo que cada cosa es lo que es. De ahí que la idea platónica, la ousía o riqueza principial de algo, se convirtiese para Aristóteles en hypo-keimenon ${ }^{8}$, lo que subyace a cada cosa como su propia naturaleza y principio de su movimiento. La idea se convirtió en substancia. De modo que ésta no es un simple individuo físico, sino un ente significativamente determinado por lo que ahora Aristóteles, en vez de idea, prefiere llamar forma de ser. Frente a todo nominalismo posterior, maestro y discípulo están pues plenamente de acuerdo en que la inteligibilidad no es un añadido lingüístico, sino despliegue, en el lenguaje ciertamente, de la interna inteligibilidad de la realidad.

Esta reformulación del platonismo, todo lo intuitiva que resulta, plantea sin embargo a Aristóteles con mucha mayor virulencia el problema del conocimiento. Para Platón está cuestión se resuelve con cierta facilidad mediante una analogía visual. Lo esencial de las cosas es su idea, que está como lo perfecto más allá del modo material e imperfecto en el que esas cosas imitan dicha perfección. Conocer es ahora «ver» esas ideas, cosa que el alma intelectiva, el nous, puede sin más hacer, porque en el orden sensible el alma está, digamos, meramente distraída; pero las cosas, en su innata tendencia hacia su propia perfección, le recuerdan aquello de lo que participan, que

[8] Cf. Met., VII, 3, 1028 b 33 ss.: «De la Substancia se habla, al menos, en cuatro sentidos principales. En efecto, la esencia, el universal y el género parecen ser substancia de cada cosa; y el cuarto de ellos es el sujeto. Y el sujeto es aquello de lo que se dicen las demás cosas, sin que él, por su parte, se diga de otra. Por eso tenemos que determinar en primer lugar su naturaleza; porque el sujeto primero parece ser substancia en sumo grado». Sigo aquí la traducción de García Yebra.

THÉMATA. Revista de Filosofía, №50 julio-diciembre (2014) pp.: 69-94

doi: 10.12795/themata.2014.i50.03 
es precisamente lo que el alma sin más entiende porque es idéntico con el alma misma. Conocer es para el alma reconocerse en el alma de las cosas que son las ideas, ellas misma connaturales al alma que conoce. No salimos del alma, en un proceso que es necesariamente reflexivo. Esta es la teoría del innatismo: entender es reconocer la esencia de las cosas, que no es otra que la del alma misma. Y ese alma de las cosas es la idea, el aspecto que las cosas ofrecen a la luz del nous. No digo que esta teoría no tenga problemas, pero es sencilla: conocer es ver; y el intelecto no es sino la luz que muestra lo visible en las cosas que verdaderamente son, allí donde ser y pensar son, como decía Parménides, lo mismo. Al decir lo que es, el pensar no sale de sí mismo.

Aristóteles mantiene ese postulado esencial del platonismo: el conocimiento en acto es lo conocido en acto ${ }^{9}$. Y ello es así tanto a nivel sensible -el sonido que emite una cosa y lo que percibe el oído, son lo mismo- como en el inteligible, donde la forma que activa el intelecto y la que determina a la cosa in rerum natura, también son idénticas. De este modo se produce la adaequatio intellectus et rei, expresión de Santo Tomás ${ }^{10}$ en la que se recoge el principio aristotélico de que en la verdad el intelecto afirma el ser o no ser de la cosa misma. El problema, sin embargo, es aquí para Aristóteles que esa identidad actual en que consiste el conocimiento, no es algo inmediato. Porque el intelecto es una facultad del alma, que es la forma activa de un sujeto individual; mientras que la forma es la actividad determinante de otra realidad substancialmente diferente. Para que ambas formas pasen a ser «la misma» hace falta un proceso que en la cosa es de desmaterialización, y en el intelecto de activación de una posibilidad multiforme mediante la cual al alma puede llegar a ser quodammodo omnia, de alguna forma todas las cosas, porque eso es el conocimiento: la connaturalidad activa del alma con aquello con lo que el alma se relaciona ${ }^{11}$.

[9] Cf. De anima, III, 4, 430 a 3-5. Leonardo Polo trata de estas cuestiones en su Curso de teoría del conocimiento, v. I. Eunsa, Pamplona 1984; lección $2^{\mathrm{a}}$.

[10] Más propiamente, en De ver. q 1, a 1, atribuye el de Aquino esta expresión a un tal Isaac Israeli. Sin embargo, J. T. Muckle en su estudio «Isaac Israeli's Definition of Truth», en: Archives d'histoire doctrinale et littéraire du moyen âge, 8 (1933), pp. 1-8, dice que no se encuentra tal definición entre sus escritos conocidos. Así que uno de los más importantes asertos de la historia del pensamiento resulta a día de hoy ser de autor anónimo.

[11] De anima, III, 9, 432 b 15 ss.: «Recapitulando ahora ya la doctrina que hemos ex- puesto en torno al alma, digamos una vez más que el alma es en cierto modo todos los entes, ya que los entes son o inteligibles o sensibles y el conocimiento intelectual se identifica en cierto modo con lo inteligible, así como la sensación con lo sensible».

THÉMATA. Revista de Filosofía, №50 julio-diciembre (2014) pp.: 69-94 doi: 10.12795/themata.2014.i50.03 


\section{Intelecto paciente, intelecto agente ${ }^{12}$}

Para entender esa identificación del alma con las cosas tendríamos dos modelos. Uno sería la asimilación que los sujetos animados hacen de su medio ambiente en los procesos de nutrición, en los que la vida incorpora elementos extraños, pero de tal modo que trans-forma esos elementos, de la forma que tienen por sí mismos -la de lechuga, por ejemplo- a la forma propia -de proteínas humanas, pongamos-que asumen al ser incorporadas. Algo parecido ocurre en los procesos de apropiación que suceden kata techné, en los que la acción subjetiva, sin destruir la alteridad de lo asimilado, también lo trans-forma, integrándolo como medio de su autorrealización; cuando, por ejemplo, hacemos de un árbol una mesa, en cualquier caso algo distinto de lo que originalmente era. Aunque haya habido intentos de entender el conocimiento según estos paradigmas - pensemos, por ejemplo, en el Demiurgo platónico- Aristóteles precisamente los rechaza, porque entiende que conocer, siendo una cierta apropiación, no es ni incorporación en sentido biológico ni transformación en el sentido tecnológico, sino un dejar ser lo conocido que lejos de destruirlo libera eso conocido en su ser propio. Es la forma de ser de lo conocido lo que tiene, por así decir, la primacía en un proceso que es verdadero alethein, desvelamiento de la physis o naturaleza conocida ${ }^{13}$. Ocurre justo al revés: el entendimiento se comporta como potencia que se asimila a las formas conocidas, que son el acto que determina formalmente dicho entendimiento. De esta forma la adaequatio ocurre ad rem, del entendimiento a la cosa. Así lo interpretará Kant cuando plantee su famosa revolución copernicana, al revés, como adaequatio rei ad intellectum ${ }^{14}$.

De este modo Aristóteles tiene que reconocer un cierto carácter pasivo en esa facultad anímica de hacerse de algún modo todas las cosas. Aparece aquí la idea de «significación»: el alma significa potencialmente todo lo que existe, pero actualmente aquello que como sello (signum) imprime su forma en esa facultad intelectiva, que de este modo se comporta como el lacre, o la tabula rasa que los niños llevaban recién planchada a la escuela, vacía de toda significación pero preparada para recibirla. Si esta fuese la última palabra de la gnoseología aristotélica, el entendimiento sería algo así como un reflejo

[12] Un magnífico estudio, con abundante material recogido sobre esta cuestión, y que me ha sido de suma utilidad, se encuentra en F. Rodríguez Valls, «Ideas para una interpretación de la doctrina de Aristóteles sobre el intelecto teórico», en: Thémata, 2001, pp. 197 ss.

[13] M. Heidegger acentúa este sentido liberador del conocimiento en «Vom Wesen der Wahrheit», en: Wegmarken, Frankfurt a. M. 1976. En un sentido perfectamente conforme con Aristóteles, como él mismo pone de manifiesto en su escrito: «Vom Wesen und Begriff der Physis. Aristoteles, Physik, B, 1", que se recoge en el mismo Sammelband. Y ello contra la interpretación que el mismo Aristóteles parece sugerir cuando compara el intelecto a la mano, como instrumento de todos los instrumentos (De anima, III, 8, 432 a 1-2)

[14] Sobre esta contraposición cf. M. Heidegger, «Vom Wesen der Wahrheit», I.

THÉMATA. Revista de Filosofía, №50 julio-diciembre (2014) pp.: 69-94

doi: 10.12795/themata.2014.i50.03 
especular de la existencia física. El empirismo se desarrolla como consecuencia de este supuesto ${ }^{15}$.

Pero Aristóteles declara insuficiente esta pasividad de un intelecto meramente potencial y receptivo. Si así fuese el entendimiento en la reproducción pasiva de la forma ajena se comportaría como mera materia. En el extremo, un geólogo terminaría por quedarse de piedra; o Tarzán sería al final uno más de los monos ${ }^{16}$. En cualquier caso el conocimiento terminaría en su contrario que es la estupefacción. Como aquel que iba al acuario, e intentando imitar al amigo que con la punta del dedo dirigía al pez de un lado a otro de la pecera para demostrar así su superioridad biológica, el amigo al volver lo encontraba boqueando mientras fijamente miraba a la carpa que tenía delante.

Por eso Aristóteles desecha tanto el modelo nutricionista del conocimiento, como este otro meramente especular. Y busca otro paradigma cognoscitivo. Y lo hace volviendo al principio platónico de reflexividad. En él, recordemos, el alma es el lugar de las ideas o formas de las cosas, de modo que al contemplarlas no sale de sí misma; y así todo conocer sería para ella re-conocer-se. Semejante alma, para la que sus contenidos no representan alteridad, no tendría entonces más límite que sí misma; sería infinita. Sin embargo, por sólido que sea el paradigma, Platón es incapaz de articularlo ontológicamente; y se mueve aquí en el reino de las intuiciones confusas, termina por hacerse un lio, y su pensamiento por descarrilar en discursos alegórico-metafóricos llenos de soles, carros alados, demiurgos, eros y demás démones. Pero algo queda, a saber, que si el conocimiento es capaz de expresar el ser de las cosas, él mismo ha de ser la forma que en todas las formas o ideas se reproduce; de manera que conoce lo en cuanto tal cognoscible; o que al conocer se reconoce. Esa reflexión en que el alma misma consiste, es para Platón sólo tentativa, una tendencia más que un acto; porque en el mundo sublunar el alma está por así decir descolgada de sí misma. De este modo, concluye melancólicamente, todo verdadero conocimiento es para el alma recuerdo o memoria de sí.

Por el contrario, Aristóteles, casi de rebote, de vuelta a la realidad de la physis se encuentra ahora en una situación mucho más sólida, porque en la cúspide de todo el edificio ontológico, como principio último, como límite que limita sin ser limitado, en vez de confusos cortejos, almas o cielos eidéticos, sitúa ahora una actividad pura, origen de toda otra actividad y en la que se

[15] Cf. J. Locke, Essay concerning human understanding, II, chap. I, 2: «Let us then suppose the mind to be, as we say, white paper void of all characters, without any ideas. How comes it to be furnished? Whence comes it by that vast store which the busy and boundless fancy of man has painted on it with an almost endless variety? Whence has it all the materials of reason and knowledge? To this I answer, in one word, from experience».

[16] Cf. De anima, III, 8; 431 b 20-432 a 14: « A su vez, las facultades sensible e intelectual del alma son en potencia sus objetos, lo inteligible y lo sensible respectivamente. Pero éstos han de ser necesariamente ya las cosas mismas, ya sus formas. Y, por supuesto, no son las cosas mismas, toda vez que lo que está en el alma no es la piedra, sino la forma de ésta».

THÉMATA. Revista de Filosofía, Nº50 julio-diciembre (2014) pp.: 69-94

doi: 10.12795/themata.2014.i50.03 
resuelven como en su principio y fin toda otra actividad natural ${ }^{17}$. Y ahora dice algo sorprendente: que al ser una actividad que termina en sí misma, que al producir se está eternamente reproduciendo, ese principio es una actividad que genera en sí sin movimiento la perfección o entelékheia que toda la naturaleza desde su materialidad intenta reproducir cuando se mueve ${ }^{18}$. Y esa actividad, que es entonces la perfección de todas las formas, es ella misma la forma de todas las formas, como la actividad que en sus productos se mantiene en sí. Semejante actividad tiene un nombre: Nous. Y en su pureza inmaterial tiene un contenido que no puede ser sino ella misma: es Noesis noeseos, el pensamiento del pensamiento, actividad como pura reflexión ${ }^{19}$.

La discusión de toda la teología aristotélica nos llevaría muy lejos, y me limito aquí a señalar mi discrepancia con las interpretaciones deístas que sitúan al Theos en una absolutez solipsista desengranada de la physis de la que es límite, principio y fin ${ }^{20}$. Antes bien, la actividad pura del primer motor, contiene en sí todas las determinaciones (entelékheiai) de todas las cosas, de tal forma que en su pura reflexividad como Noesis noeseos, conociéndose a sí mismo conoce también «todas las cosas» según su forma de ser, en la que de modo potencial se refleja la misma perfección del acto puro. Y esto no ocurre porque el Nous divino «reciba» dichas formas, sino precisamente porque como forma de todas las formas, como actividad de todos los actos, las activa y produce él mismo ${ }^{21}$.

De este modo, frente a la idea de una intelectualidad receptiva, ligada al contacto físico y a las modificaciones sensibles de carácter corporal que son propias de un alma materializada y limitada a la particularidad del cuerpo, aparece aquí como contrapunto la de una intelectualidad pura, por sí misma activa, a priori o innata. Y toda la doctrina del intelecto agente tiene aquí su sentido. Porque la pasividad receptiva por la que el intelecto recibe las formas

[17] Met. XII, 6, 1071 b 12 ss.

[18] Cf. De anima, II, 4, 415 a 27 ss.: «Y es que para todos los vivientes que son perfectos -es decir, los que ni son incompletos ni tienen generación espontánea- la más natural de las obras consiste en hacer otro viviente semejante a sí mismos -si se trata de un animal, otro animal, y si se trata de una planta, otra planta- con el fin de participar de lo eterno y lo divino en la medida en que les es posible: todos los seres, desde luego, aspiran a ello y con tal fin realizan cuantas acciones realizan naturalmente».

[19] Met. XII, 9, 1074 b 38.

[20] Anthony Flew, es el último de los que han querido interpretar así a Aristóteles, apoyándose en él en su conversión filosófica desde el ateísmo hacia posiciones expresamente deístas. Cf. G. R. Habermas, «Antony Flew's Deism Revisited. A Review Essay on There Is a God», en: Philosophia Christi, 9, 2 (2007), pp. 431 ss.

[21] Lejos de toda pasividad deísta, considera Aristóteles que Dios, que es pensamiento puro, es forma de todas las formas, como el alma. Y asimila esta, y tras ella al nous en general, a la mano, que es instrumento de todos los instrumentos (De anima, III, 8, 432 a 1-2). Por eso, si hay un poietikós, ése es el Theos aristotélico. No es un aburrido observador, sino esencialmente el Hacedor.

THÉMATA. Revista de Filosofía, №50 julio-diciembre (2014) pp.: 69-94 doi: 10.12795/themata.2014.i50.03 
de las cosas, no se activa directamente en ese proceso psíquico de recepción, si no se presupone la actividad primera, ilimitada, que es la encargada de explicitar lo que en esa recepción está sólo potencialmente contenida. El alma humana, en la medida en que está incorporada y ligada a la materia, no conoce en sí misma todas las cosas. Sólo llega a saber de pájaros, por ejemplo, en la medida en que tiene contacto físico y sensible con esas criaturas. De ahí el adagio: nada hay en el intelecto que antes no estuviese en los sentidos. Ámbito en el que, por otra parte, los pájaros no se manifiestan de cualquier manera, sino como lo que son: no croan, pian; no nadan, vuelan; no paren, ponen huevos, etc. Y así, en su manifestación sensible, que los sentidos internos reconstruyen y organizan, va implícita la forma natural.

Pero esto no es suficiente para dar cuenta del carácter formal del conocimiento capaz de expresar el ser. Los pájaros se manifiestan igualmente tal y como son ante sus congéneres, de tal modo que recogiendo esa información, éstos organizan su conducta de forma acorde. De ahí toda la ciencia de la etología. Igualmente se manifestarían según su forma ante una cámara de video y un receptor acústico que situásemos delante del nido. Pero ni esos receptores, ni siquiera los otros pajaritos, por más que éstos últimos actúen conforme a lo que perciben de sus iguales, llegarán nunca a «saber de pájaros». Y no por la debilidad de sus medios perceptivos. Lo que falta es la capacidad de, más allá de la organización de esa multiplicidad de datos sensibles (que si la tienen los otros pájaros), reproducir, no materialmente sino en la formalidad de su mismo intelecto, esa pluralidad sensible como la forma de ser según la que los pájaros actúan. Y esa es una capacidad productiva tal que lo que en ella se re-produce es, junto a la forma implícita de los pájaros, la misma forma del pensamiento en absoluto. Eso es el nous poeitikós.

\section{De luces y conceptos}

Poco más dice Aristóteles en los famosos párrafos del De anima. Y lo que añade más bien contribuye al desconcierto. Esta actividad productiva del nous, supone en el alma humana una facultad o capacidad que la sitúa a medio camino entre la receptividad psíquica animal y la pura actividad reflexiva del Theos. Y a la hora de cartografiar ese territorio el de Estagira se vuelve a perder en metáforas y alegorías. Y así compara el intelecto agente a la luz que activa en el ámbito visual las imágenes y colores que percibimos y que vienen dados (aunque no activados) en los datos sensibles que recibi$\operatorname{mos}^{22}$. La consecuencia es, una vez más, que todo el proceso intelectivo queda analógicamente asimilado al sentido de la vista. Por otra parte, es cierto que

[22] Cf. De anima, III, 5, 430 a 14 ss.: "Así pues, existe un intelecto que es capaz de llegar a ser todas las cosas y otro capaz de hacerlas todas; este último es a manera de una disposición habitual como, por ejemplo, la luz: también la luz hace en cierto modo de los colores en potencia colores en acto».

THÉMATA. Revista de Filosofía, №50 julio-diciembre (2014) pp.: 69-94 doi: 10.12795/themata.2014.i50.03 
la metáfora es fuerte y, valga la redundancia, ilustrativa; como testifica su enorme éxito histórico (san Agustín, sto. Tomás, Ilustración, Hegel, Heidegger), hasta llegar a los comics, que recurren al bocadillo de la bombilla para significar esa idea que irrumpe desde fuera para "aclarar» una, de otra forma confusa, pluralidad de datos. Pero, trascendiendo todo límite negativo (de sombras) que la convierte en imagen concreta, esa luz es el límite positivo que limita sin ser limitado, es pues algo puro, sin mezcla, eterno, y absoluto o separado (horistón), y por tanto divino ${ }^{23}$.

Este carácter, si no separado sí al menos separable y posiblemente eterno del nous, le viene muy bien a la escolástica cristiana para apoyar argumentalmente la inmortalidad del alma; no así su carácter infinito y puro, que nos llevaría a algo parecido a un panteísmo gnoseológico transpersonal. De ahí los esfuerzos de Tomás de Aquino por reindividualizar el intelecto agente ${ }^{24}$; tarea que no deja de ser problemática, pues es difícil dejar de lado esa dimensión infinita que parece le es connatural.

Y no deja de haber aquí tendencias contradictorias. Por un lado, recurrir a la luz nos sugiere un espacio abierto, compartido, "agoriforme»; en el que todo comunica a la vez que queda trascendido en una síntesis lógica. Es el espacio en el que, nunca mejor dicho, tiene lugar el desvelamiento o aletheia: la verdad, en la que las cosas se manifiestan en la identidad actual en la que son uno lo conocido y los cognoscentes. Pero ese espacio luminoso es ahora también reflexivo; recoge la pluralidad universal en una identidad formal en la que esa diversidad se guarda en un seno anímico que se hace «de algún modo todas las cosas». Y así, como lo guardado en esa intimidad, la verdad iluminada, siguiendo ahora una metáfora contraria, por así decir ginecológica, se convierte en lo concebido, en concepto ${ }^{25}$. Y no como si esa interioridad fuese mero almacén de lo recibido desde fuera, sino en cuanto eso mismo recibido, sin perder su forma propia, queda también trans-formado por la forma misma de la interioridad intelectiva, por sí misma activa y fecunda.

¿En qué quedamos? ¿Es el intelecto espacio abierto y compartido, o más bien ámbito recoleto y reflexivamente cerrado? La síntesis de estas dos

[23] Cf. Ibid., 430 a 17 ss.: «Y tal intelecto es separable, sin mezcla e impasible, siendo como es acto por su propia entidad. Y es que siempre es más excelso el agente que el paciente, el principio que la materia».

[24] Cf. principalmente el opúsculo De unitate intellectu contra averroistas. Cf. J. M. Barrio Maestre, "La disputa averroismo-tomismo en el op.>De unitate intellectus contra averroistas»", en Anales del Seminario de Historia de la Filosofía, 8 (1986/89) pp. 131 ss.

[25] De nuevo Heidegger ha intentado recuperar ese sentido «abierto» del pensamiento, oponiéndolo a la «cerrazón» conceptual, que el tiende a atribuir al subjetivismo moderno. Cf. p. ej. Was heisst Denken. Pero no se trata de una contraposición en la que estuviésemos obligados a optar por un término contra el otro: concepto y verdad. Justo en el sentido heideggeriano de alétheia como desvelamiento, ambos términos se requieren mutuamente. Y es en esta tensión entre interioridad y apertura donde se manifiesta en su unidad el sentido de ser y pensar.

THÉMATA. Revista de Filosofía, №50 julio-diciembre (2014) pp.: 69-94

doi: 10.12795/themata.2014.i50.03 
tendencias, de la misma dirección y sentidos opuestos, es el concepto escolástico de «intencionalidad», característica propia de los fenómenos cognoscitivos y más propiamente intelectuales, por la que el acto inteligible está por un lado definido pasivamente por la forma propia de la substancia conocida, y por otro por la forma universal, origen activo de la reflexividad intelectual, por la que ese acto lo es al mismo tiempo de la mente cognoscente ${ }^{26}$.

Ciertamente la escolástica desarrolla así ampliamente la doctrina aristotélica del intelecto, liberándola de esa tentación alegórica propia de las teorías todavía adolescentes. Corre sin embargo el riesgo de perderse ahora en la artificiosidad conceptual. Todo el que haya intentado seguir los argumentos escolásticos a través de esa maraña de facultades, forma real, acto inteligible, especie impresa, expresa, fantasma, intención, suposición, primeros principios, concepto abstracto, género, diferencia, definición, y todos los etcéteras que genera la pasión por los distingos, reales, de razón, relaciones trascendentales y demás, no puede por menos que admirar la sutileza a que llegó el afán por la disputatio. Y sin embargo, yo al menos me quedo frío ante esa especie de mecanicismo argumental en que los conceptos terminan por ahogar una teoría del conocimiento que encerrada en sí misma al final más bien oscurece lo que quería ilustrar. Entre la ingenuidad alegórica de los viejos maestros griegos y la sofisticación escolástica medieval, yo no sé con cuál quedarme.

\section{Entendimiento y autoconciencia: la síntesis suprema de las categorías en Kant}

En el desconcierto, puede ser aconsejable un rodeo por otros paisajes teóricos, a primera vista muy divergentes, pero que, al fin y al cabo por tratarse en ellos de eso mismo que nos interesa, pueden arrojar luz -seguimos en la metáfora- para entender lo que unos y otros pretenden decir.

Digamos de entrada que, no pocas veces, una de las primeras tareas de todo hermeneuta consiste en salvar a los autores de las malinterpretaciones de que ellos mismos se hacen culpables. Kant es uno de los peores en este sentido. Y no sólo por su afición a la argumentación y conceptografía escolásticas, que haría las delicias del más sofisticado maestro del siglo XIII. También por su empeño en interpretarse a sí mismo como continuador de Descartes, a partir de lo que él llama «revolución copernicana», en la que se invierte el centro de

[26] Como es sabido es F. Brentano el que recupera esta idea escolástica de «intencionalidad» para hacer de ella la característica propia de los fenómenos psíquicos. Cf. Psychologie vom empirischen Standpunkt. 1874, I, p. 124, De ahí, a través de Husserl, la recoge también M. Heidegger, cuya obra en muchos sentidos puede ser considerada como una ontología de la intencionalidad en la que se pone de manifiesto la original unidad de ser y pensar. Cf. mi trabajo Die Auflösung des Seins. Die Entwciklung einer phänomenologischen Ontologie im Denken Martin Heideggers. Wien: VWGÖ, 1983.

THÉMATA. Revista de Filosofía, №50 julio-diciembre (2014) pp.: 69-94 doi: 10.12795/themata.2014.i50.03 
gravedad fundante de la teoría del conocimiento, desde un objeto supuestamente autosuficiente en su determinación formal, a un sujeto que va a asumir el protagonismo de esa constitución formal en un proceso de síntesis de la experiencia ${ }^{27}$. La malinterpretación sugeriría aquí que Kant es uno más de los subjetivistas seguidores de Descartes, en una línea que culmina en Berkeley disolviendo el ser en la pura percepción (esse est percipi); «mentalismo» éste, más que subjetivismo, desde el que se ha interpretado toda la gnoseología y ontología modernas, y el idealismo posterior. Como ya dijimos, frente a la aristotélica adaequatio intellectus ad rem, se trataría ahora de una inversa adaequatio rei ad intellectum.

Pero a mi modo de ver esta tendencia hermenéutica es incorrecta, porque Kant hace una teoría del conocimiento, no como Descartes partiendo de la suficiencia reflexiva de un sujeto separado que contuviese en sí a priori, de forma innata, todos los elementos necesarios para su veracidad. Antes bien, el medio en el que Kant desarrolla su teoría es la ex-periencia. No se insistirá nunca lo suficiente en el carácter esencialmente finito que Kant quiere acentuar en el conocimiento ${ }^{28}$, por el que todo el contenido de éste procede de fuera, y ciertamente lo limita al ámbito de la facticidad. Por sí mismo el entendimiento sólo dispone del despliegue analítico de su propia formalidad lógica, que carece de valor informativo. Dicho de otra forma, el contenido cognoscitivo es una modificación de la experiencia que ésta «recibe» de fuera, pasivamente, y que limita ese conocimiento a eso que ahí fuera sucede $^{29}$. A partir de esa pluralidad material, el conocimiento no es sin embargo simple reflejo de una diversidad sensible en sí misma caótica. Todo conocimiento, es una «composición» (de lugar, decimos), un syn-thesein ${ }^{30}, \mathrm{y}$

[27] Cf. Crítica de la razón pura, Prólogo a la $2^{\text {a }}$ edición, B XVI s.

[28] L. Polo ha examinado el planteamiento kantiano en «La crítica kantiana de la razón», en Estudios de filosofía moderna y contemporánea. Eunsa, Pamplona 2012; c. V.

[29] Esa esencial receptividad es lo que, al igual que en Aristóteles, da al conocimiento su carácter esencialmente sensible en el origen: «La capacidad (receptividad) de recibir representaciones, al ser afectados por los objetos, se llama sensibilidad. Los objetos nos vienen, pues, dados mediante la sensibilidad y ella es la única que nos suministra intuiciones» (A19/B33). Seguimos la traducción de Pedro Ribas.

[30] Cf. Crítica de la razón pura, B130: «Pero la combinación (conjunctio) de una variedad en general nunca puede llegar a nosotros a través de los sentidos ni, por consiguiente, estar ya contenida, simultáneamente, en la forma pura de la intuición sensible. En efecto, es un acto de la espontaneidad de la facultad de representar. Como esta facultad ha de llamarse entendimiento, para distinguirla de la sensibilidad, toda combinación (seamos o no conscientes de ella, trátese de combinar lo vario de la intuición o varios conceptos, sea, en el primer caso, combinación de la intuición sensible o de la no sensible) constituye un acto intelectual al que daremos el nombre general de síntesis. Con ello haremos notar, a la vez, que no podemos representarnos nada ligado en el objeto, si previamente no lo hemos ligado nosotros mismos, y que tal combinación es, entre todas las representaciones, la única que no viene dada mediante objetos, sino que, al ser un acto de la espontaneidad del sujeto, sólo puede ser realizada por éste».

THÉMATA. Revista de Filosofía, №50 julio-diciembre (2014) pp.: 69-94 doi: 10.12795/themata.2014.i50.03 
los elementos de esa síntesis condicionante (be-ding-ende) pueden ser deducidos como condiciones de su posibilidad.

Lo que sí es Kant, más que subjetivista o mentalista, es nominalista. Los hechos que afectan a nuestra experiencia no son por sí mismos significativos, no tienen por sí una forma que se tuviese que reflejar en el entendimiento para garantizar la veracidad de éste. Y si ahora resulta que esa composición o síntesis de la experiencia no es arbitraria sino que se sigue de reglas lógicas que son válidas para todo sujeto de una experiencia posible, entonces esa regularidad o validez constatable en la experiencia depende de las formas de la citada síntesis. Formas que no proceden ahora del contenido de la experiencia, sino a priori de la misma dinámica sintética.

Lo que sigue son lugares comunes en cualquier manual. Esas formas «funcionan» a nivel básico de la sensibilidad, en tanto que toda experiencia "tiene lugar», esto es, ocurre "fuera», y está por tanto sometida a las leyes propias de lo que Kant llama la intuición pura del espacio; y en tanto que eso que tiene lugar también "sucede», igualmente a las del tiempo. Espacio y tiempo son formas a priori que la experiencia "añade» en un despliegue de su espontaneidad a priori. Pero se trata de la espontaneidad propia de un sujeto limitado por su esencial receptividad a un fuera y a un antes y después. Son por así decir formas de disponer de lo indisponible, de eso que, procediendo en su materialidad de un más allá ("cosa en sí», lo llama Kant), limita toda experiencia efectivamente al espacio y el tiempo, donde ese material se articula como «fenómeno», como lo que aparece. A continuación, ese material sensible, se organiza por el lenguaje mediante la actividad judicativa; en ella las intuiciones sensibles se subsumen y unifican, se sintetizan, bajo conceptos generales. Estos conceptos pueden tener origen en la misma experiencia; pero hay otros que dependen, no de la experiencia concreta, sino de las formas posibles de la facultad de juzgar en absoluto. Se trata entonces de las "categorías», que son los conceptos básicos que definen la forma de entender (de subsumir intuiciones bajo conceptos), que son también las formas básicas de juzgar, que es decir el ser. De modo que las categorías, como condiciones de posibilidad para la intelección de los objetos de experiencia, son a la vez las condiciones de posibilidad de su objetividad mis$\mathrm{ma}^{31}$. Porque, en efecto, el resultado de esa síntesis que hace el entendimiento, mediante sus formas propias, del material empírico que facilita la sensibilidad, es lo que Kant denomina «objeto». Se trata en él de la integración lógica de la pluralidad experiencial tal y como se articula según dichas formas básicas de percibir sensiblemente y luego de juzgar y conocer propiamente. Esa síntesis, que depende en cuanto a su contenido del material recibido pasivamente en la experiencia, en cuanto a su forma depende de una actividad pura a priori,

[31] Cf. Crítica de la razón pura, «Las condiciones de posibilidad de la experiencia en general constituyen, a la vez, las condiciones de posibilidad de los objetos de la experiencia y por ello poseen validez objetiva en un juicio sintético a priori» (B198, A159)

THÉMATA. Revista de Filosofía, $\mathrm{N}^{\circ} 50$ julio-diciembre (2014) pp.: 69-94 doi: 10.12795/themata.2014.i50.03 
espontánea, dice Kant, que tiene su origen, no en el objeto, sino en el lado subjetivo de la experiencia.

¿Y por qué nos ocupamos de esto cuando lo que nos interesa es el intelecto agente en Aristóteles? Pues porque Kant apunta en la misma dirección y la confluencia entre ambos pensadores bien puede servir para su mutuo esclarecimiento. Uno de los posibles errores de interpretación en Kant sería entender las formas de la síntesis experiencial -intuiciones de la sensibilidad, categorías del entendimiento y posteriormente, con sus reglas propias, las ideas de la razón- como instancias abstractas cuya principal función fuese justificar las condiciones de posibilidad de juicios sintéticos con validez a priori. Se trataría de ver las condiciones de una posible epistemología, como alternativa a una ontología general de carácter metafísico. De este modo, la ciencia sería el conocimiento posible para una subjetividad igualmente abstracta, que sería algo así como el sujeto universal de la actividad científica. El sujeto trascendental kantiano y el intelecto agente "eterno y separado» de Averroes serían una misma cosa. Sin embargo, pese a los intentos neokantianos de promover esta interpretación, se trata en Kant de una vía muerta; porque en la cima focal de la actividad sintética, Kant no sitúa las formas de un entendimiento posible, sino una actividad pura a priori, que Kant denomina "apercepción trascendental» y que supone, no un "se piensa» abstracto, sino un "yo pienso en absoluto» que tiene que poder acompañar a todas mis representaciones ${ }^{32}$. Y no podía ser menos, porque la síntesis de la experiencia no es una mera clasificación formal, sino una con-posición, lo que quiere decir, una actividad pura, que trasciende a toda representación y que no tiene más origen que sí misma. Dicho de otra forma: la última condición de posibilidad de la síntesis de la experiencia para todo sujeto, no es una posibilidad, no es algo de un sujeto a su vez también posible. Lo que Kant llama deducción trascendental que asciende desde los objetos

[32] Cf. Crítica de la razón pura, B132-133: « El Yo pienso tiene que poder acompañar todas mis representaciones. De lo contrario, sería representado en mí algo que no podría ser pensado, lo que equivale a decir que la representación, o bien sería imposible o, al menos, no sería nada para mí. La representación que puede darse con anterioridad a todo pensar recibe el nombre de intuición. Toda diversidad de la intuición guarda, pues, una necesaria relación con el Yo pienso en el mismo sujeto en el que se halla tal diversidad. Pero esa representación es un acto de la espontaneidad, es decir, no puede ser considerada como perteneciente a la sensibilidad. La llamo apercepción pura para distinguirla de la empírica, o también apercepción originaria, ya que es una autoconciencia que, al dar lugar a la representación Yo pienso (que ha de poder acompañar a todas las demás y que es la misma en cada conciencia), no puede estar acompañada por ninguna otra representación. Igualmente, llamo a la unidad de apercepción la unidad trascendental de la autoconciencia, a fin de señalar la posibilidad de conocer a priori partiendo de ella. En efecto, las diferentes representaciones dadas en una intuición no llegarían a formar conjuntamente mis representaciones si no pertenecieran todas a una sola autoconciencia. Es decir, como representaciones mías (aunque no tenga conciencia de ellas en calidad de tales) deben conformarse forzosamente a la condición que les permite hallarse juntas en una autoconciencia general, porque, de lo contrario, no me pertenecerían completamente. De esta conexión originaria pueden extraerse muchas consecuencias».

THÉMATA. Revista de Filosofía, №50 julio-diciembre (2014) pp.: 69-94

doi: 10.12795/themata.2014.i50.03 
de experiencia hacia las condiciones de posibilidad de su síntesis, termina la cadena de condiciones en un absoluto incondicionado: la última condición de posibilidad, ya no es una posibilidad sino una actividad, a saber, una tal actividad original e incondicionada. No es potencia, sino actividad pura a priori ${ }^{33}$.

Esa instancia suprema, última e incondicionada condición de todo entendimiento posible, es ciertamente una forma, y en cuanto tal se extiende sobre el contenido total de la experiencia. Es más, es la forma misma de la síntesis por la que esta experiencia no se da dispersa en la pluralidad de sus contenidos pasivamente recibidos; es la forma por la que en toda experiencia surge un sujeto que activamente se apropia de la totalidad de dichos contenidos; apropiación por la que éstos pasan a ser suyos. Sin ella no hay experiencia, que tiene que ser siempre $m i a^{34}$.

De este modo podemos sacar algunas conclusiones que en la contraposición nos ayudan a entender algunas cosas, de lo que es la intelección en general, y al final también de lo que, por similitud y diferencia, Aristóteles puede entender por intelecto agente. Digamos en primer lugar que para Kant no hay algo parecido a lo que Aristóteles denomina intelecto paciente. Porque la receptividad se limita en Kant al material empírico. Tiene que ver con su radical nominalismo, que hace de la generalidad abstracta una "construcción». La formas de objetivación no son para él «formas de ser» de una realidad conocida; son sólo formas de la síntesis según las cuales el entendimiento produce a priori (aunque sólo formalmente) los objetos de experiencia. Por consiguiente, no cabe esperar en el proceso cognoscitivo una identidad actual sujeto-objeto, ni nada parecido a una adaequatio intellectus et rei. La realidad sigue siendo al final de dicho proceso un «X ignotum». Con los problemas que eso supone: básicamente que la experiencia resulta que no es verdadero conocimiento del

[33] Cf. Crítica de la razón pura, A108: «(...) el psiquismo no podría pensar, y menos a priori, la identidad del Yo en medio de la diversidad de sus representaciones, si no tuviese presente la identidad de su acto, identidad que somete toda síntesis de aprehensión (que es empírica) a una unidad trascendental y que hace posible su interconexión según reglas a priori».

[34] Cf. Crítica de la razón pura, B134-135: «El pensamiento de que todas esas representaciones dadas en la intuición me pertenecen equivale, según eso, al de que las unifico en una autoconciencia o puedo, al menos, hacerlo. Este pensamiento no es todavía la conciencia de la síntesis de las representaciones, pero sí presupone la posibilidad de tal síntesis. Es decir, sólo llamo mías todas las representaciones en la medida en que pueda abarcar en una conciencia la diversidad de las mismas. De lo contrario, tendría un yo tan abigarrado y diferente como representaciones -de las que fuese consciente- poseyera. Como dada a priori, la unidad sintética de lo diverso de las intuiciones constituye, pues, el fundamento de la identidad de la misma apercepción que precede a priori a todo mi pensamiento determinado. Pero la combinación no se halla en los objetos ni puede ser tomada de ellos mediante percepciones, pongamos por caso, y asumida así por el entendimiento. Al contrario, esa combinación es obra exclusiva del entendimiento, que no es, a su vez, más que la facultad de combinar a priori y de reducir la diversidad de las representaciones dadas a la unidad de apercepción. Este principio, el de la apercepción, es el más elevado de todo el conocimiento humano».

THÉMATA. Revista de Filosofía, $\mathrm{N}^{\circ} 50$ julio-diciembre (2014) pp.: 69-94

doi: 10.12795/themata.2014.i50.03 
mundo, sino producción de objetividad, sólo a partir del material empírico, en sí mismo no significativo, que recibimos de fuera. Pero lo que sí hay en Kant es un intelecto agente, como responsable de la síntesis formal de la experiencia. Es más, situándose la pasividad en el mero carácter empírico de la experiencia, esa síntesis es el momento activo que aporta el sujeto trascendental, a cuya última forma remiten todas las formas de la construcción sintética, a nivel de la sensibilidad, del entendimiento y de la razón.

Forma de todas las formas, llamaba Aristóteles al intelecto agente. Y ahora es Kant quien nos aclara el sentido de esa última "forma formarum». Esa forma es la forma pura del Yo. Y la actividad en que ese Yo consiste, como actividad pura no limitada en sí misma por condición alguna, es la reflexión por la que en todos sus contenidos empíricos el Yo se reconoce a sí mismo, elevando toda conciencia a autoconciencia. Las formas a priori que hemos visto de abajo a arriba en el proceso cognoscitivo, son las formas que tiene ese actividad pura del Yo de acompañar todas sus representaciones y por tanto de poder reconocerse en ellas. Pensamiento, intelección, sensibilidad, son los resultados de ese proceso sintético en el que la pura actividad del Yo por así decir se materializa formalizando el material sensible. La experiencia, como algo, ahora sí, potencialmente inteligible, es en su conjunto el resultado de esa original reflexividad en que consiste como forma de todas las formas la actividad pura del Yo.

Suena bien, suena platónico: conocer es reconocerse; es para el alma -para el Yo, matiza ahora Kant- la forma por la que en medio de la dispersión material, del caos empírico, el alma que es ahora sujeto recupera la identidad consigo misma en sus propios contendidos, en la circunstancia de su mundanidad. De donde podemos concluir: la intelección es el acto concreto en el que, ya sea el mero material empírico sin significación propia (para Kant), ya sea (para Aristóteles) las formas implícitamente trasmitidas por los sentidos externos e internos (nihil est in intellectu quod prius non fuerit in sensu) se activan en dicha recepción de modo que el pensamiento sea lo que originalmente es y quiere ser: noesis noeseos. Pensar es ver el mundo como Dios lo ve, en sí mismo; y es así el modo en el que más propiamente lo imitamos y nos hacemos imagen de su infinita actividad.

La forma de todas las formas es aquella en la que el Yo como actividad pura se reconoce en los contenidos de su experiencia y recupera la reflexividad incondicionada materialmente perdida en el carácter empírico de dicha experiencia ${ }^{35}$. En definitiva, lo que Kant quiere dejar claro es que el proceso

[35] Cf. Crítica de la razón pura, A130: «En efecto, éstos constituyen, en cuanto fenómenos, un objeto que se halla sólo en nosotros, ya que una simple modificación de nuestra sensibilidad no puede existir fuera de nosotros. La misma representación de que todos estos fenómenos y de que, consiguientemente, todos los objetos de los que podemos ocuparnos se hallan en mí (es decir, constituyen determinaciones de mi Yo idéntico) expresa la necesidad de una completa unidad de tales determinaciones en el interior de una misma y única apercepción. Pero esta unidad de la conciencia posible constituye también la forma de todo conocimiento de los objetos (conocimiento a través del cual pensamos lo diverso como perteneciente a un único objeto). Así, pues, el modo según el cual

THÉMATA. Revista de Filosofía, №50 julio-diciembre (2014) pp.: 69-94

doi: 10.12795/themata.2014.i50.03 
cognoscitivo no es, como pretendía Hume, una pura recepción pasiva de impresiones sensibles. El sujeto no se limita a ser un perceptions bundle que reflejase un mundo exterior, sino que es más bien reflejo de una actividad incondicionada, en la que, decíamos, el sujeto quiere reconocerse a sí mismo. Y utilizo el verbo «querer» precisamente para señalar el carácter puro y espontáneo de esa actividad sintética, que frente a la receptividad de la experiencia en su carácter empírico, bien podemos llamar ahora libertad. La experiencia no es entonces un simple cogito cartesiano, una conciencia de la que se pudiese deducir un ser (ergo sum), sino un ser sí mismo, que trasciende como una acción incondicionada, como libertad, el limite material, sensible, de su facticidad histórica. No somos porque conocemos, sino, al revés, conocemos porque somos, a saber, actividad reflexiva pura, espontánea ${ }^{36}$; porque somos libres ${ }^{37}$.

Y lo mismo ocurre en Aristóteles. Es cierto que para el Estagirita hay un momento receptivo, no sólo en la sensibilidad sino también en el entendimiento. Porque la forma de lo conocido es también reflejo de su (del objeto) propia actividad interna, en la que eso conocido también actúa por sí, esto es, según su naturaleza. Pero la plasticidad receptiva del entendimiento posible es incapaz de dar cuenta de la actividad en que el mismo conocimiento consiste. La forma natural implícita en la experiencia sensible, tiene que ser activada, y aquí se requiere igualmente una actividad que por parte del alma trasciende todo límite, que tiene pues un carácter igualmente trascendental, incondicionado, a priori y libre.

Por ejemplo, un ordenador dotado de los sensores oportunos pude procesar a partir de su medio todo tipo de información, en la que está latente la

la diversidad contenida en la representación sensible (intuición) pertenece a una conciencia es algo que, en cuanto forma intelectual del conocimiento del objeto, precede siempre a tal conocimiento. Este modo mismo constituye un conocimiento formal a priori de todos los objetos, en la medida en que sean pensados (categorías). La síntesis de esos objetos mediante la imaginación pura y la unidad de todas las representaciones en relación con la apercepción originaria preceden a todo conocimiento empírico. Si los conceptos puros del entendimiento son posibles, más todavía, necesarios, en relación con la experiencia, ello se debe tan sólo a que nuestro conocimiento no se ocupa más que de fenómenos cuya posibilidad reside en nosotros mismos y cuya combinación y unidad (en la representación de un objeto) sólo existe igualmente en nosotros».

[36] Por eso, la unidad reflexiva de la conciencia, en su pura espontaneidad, precede a toda objetivación: «La unidad sintética de la conciencia es, pues, una condición objetiva de todo conocimiento. No es simplemente una condición necesaria para conocer un objeto, sino una condición a la que debe someterse toda intuición para convertirse en objeto para mí. De otro modo, sin esa síntesis, no se unificaría la variedad en una conciencia» (Crítica de la razón pura, B139)

[37] Naturalmente, es J. G. Fichte, el que lleva esta idea de la prelación activa del Yo a sus últimas consecuencias. Cf, Grundlage der gesamten Wissenschaftslehre (1794), § 1, 7. Meiner: Hamburg, 1989. P. 16 (I, 96): «La posición del Yo por sí mismo es su más pura actividad. El Yo se pone a sí mismo, y así es por fuerza de ese mismo ponerse. Y al revés, el Yo es, y pone su ser por fuerza de su mero ser. Es a la vez la acción (Handlung) y el producto de la acción; lo que actúa (das Tätige) y lo producido por esa actividad. Acción (Handlung) y hecho (Tat) son uno y lo mismo. Y por eso Yo soy es la expresión de una acción reflexiva (Tathandlung)».

THÉMATA. Revista de Filosofía, Nº50 julio-diciembre (2014) pp.: 69-94

doi: 10.12795/themata.2014.i50.03 
forma de ser de las cosas que modifican materialmente esos sensores. Pero conocer, o al menos inteligir, no es, como muy bien ve Kant, un simple proceso de esos datos sensibles. Un ordenador puede incluso ser más eficiente en esa pasividad procesual. Pero no «se entera»; lo que tiene que ver con hacerse «entero», con totalizar esa información en un acto reflexivo en el que, de pronto, como una luz, surge lo conocido como forma a partir de la cual decimos lo que es y lo que no es. Y esa totalización, de nuevo, es una tarea que sólo puede realizar la actividad reflexiva y libre que como forma de todas las formas ilumina, no lo que las cosas hacen, sino lo que son, como aquello que a la vez en unidad actual podemos pensar. Un ordenador no conoce, porque él mismo no existe libremente como sujeto. En eso le gana un simple niño capaz ya de reconocerse a sí mismo en lo que le sucede.

\section{La expresión y la fuerza}

Uno de los pasajes más enrevesados de la ya enrevesada Fenomenología del espíritu es el titulado «Fuerza y entendimiento, apariencia y mundo suprasensible». Requiere sin embargo de una especial atención porque se sitúa justo en el punto de inflexión en que, por el lado subjetivo la conciencia deja de ser simple percepción y se convierte en autoconciencia, mientras que por el otro lado el mundo sensible pasa de ser un hecho bruto a expresión de un ley inteligible cuyo despliegue abarca la totalidad de lo real. Y ello de tal forma que, por un lado autoconciencia y por otro mundo ideal, se muestran como dos momentos necesario del mismo despliegue del espíritu, reproduciendo a nivel del entendimiento la misma dualidad que a nivel de la sensibilidad se daba como contraposición de «la percepción» y "la cosa»" ${ }^{38}$. Por otra parte, eso que aquí Hegel llama "fuerza y entendimiento», lo denominará en La ciencia de la lógica Idea, como totalidad refleja de la que, por un lado el Concepto y por otro la Esencia, se mostrarán como los polos subjetivo y objetivo del mismo Absoluto reflexivo que en su interna diferencia mantiene la identidad consigo mismo.

Naturalmente no vamos a entrar aquí en las complejidades de la dialéctica. Lo que me interesa de Hegel y del citado pasaje es que el suabo trata en él una cuestión decisiva para nuestra comprensión de la idea aristotélica de intelección, mientras apunta una crítica implícita al planteamiento kantiano. Se trata precisamente de la identidad actual de pensamiento y ser que ha de tener lugar para que la conciencia sea cognoscitiva y la realidad lo conocido en ella. Y esa identidad no se da en Kant. Hasta el punto de que en él se sustituye, el criterio de verdad como adecuación, por el criterio de coherencia interna del sujeto consigo mismo; lo que se consigue mediante la formalización a priori del material sensible de la experiencia. Hegel sabe bien que ese criterio es insufi-

[38] Cf. Phänomenologie des Geistes, A, II. Ed. Suhrkamp, pp. 93 ss.

THÉMATA. Revista de Filosofía, Nº50 julio-diciembre (2014) pp.: 69-94 doi: 10.12795/themata.2014.i50.03 
ciente, porque termina en una pura identidad del entendimiento consigo mismo. Y en el fondo Kant también lo sabe, hasta el punto de que, más allá de la experiencia, la cosa en sí, como foco activo de las modificaciones de la experiencia, termina por tener el mismo carácter nouménico e incondicionado de la actividad pura del Yo. Propiamente no sería una «cosa", sino una especie de "otro Yo» en la forma de negatividad. La síntesis de los dos noumena, subjetivo uno y objetivo (aunque también igualmente subjetivo) el otro, síntesis en la que el Yo se reconocería a sí mismo, no sólo en la experiencia empírica sino en absoluto en una síntesis de mundo, alma y Dios, constituye lo que él llama el Ideal de la razón pura, tan inalcanzable fácticamente como irrenunciable formalmente ${ }^{39}$. Sería algo así como el reconocimiento que haría de sí el sujeto trascendental en la totalidad, no experienciada sino experienciable, de todas las cosas, allí donde esas cosas ya no serían límite empírico de la experiencia sino autoposición reflexiva de un sujeto absoluto. Y esta síntesis es la que Hegel quiere ver realizada, no ya en la forma de experiencia empírica, sino, más allá de ésta, como sistema en el que se despliega la totalidad del Absoluto; totalidad en la que, por así decir, Dios se reconocería a sí mismo en todas las cosas. Una vez más, el conocimiento intelectivo, como activación de las formas posibles en la identidad reflexiva del sujeto, sería la forma actual de esa noesis noeseos, de la existencia como reflexión pura, que Aristóteles sitúa como actividad original de todas las cosas.

Como decía, no vamos a seguir las complejidades del citado pasaje de la Fenomenología del espíritu ${ }^{40}$. Lo que básicamente me interesa señalar es el elemento al que Hegel da todo el protagonismo en el proceso por el que la conciencia se reencuentra consigo misma en su diferencia ${ }^{41}$. Esa diferencia se muestra primero, en la forma de simple percepción, como la cosa. Y después como entendimiento en la ley que rige el despliegue de la naturaleza; también vista como mundo suprasensible, en el que más propiamente la conciencia emerge como autoconciencia. Desde el punto de vista newtoniano en el que aquí se sitúa Hegel, esa forma intelectual en que las cosas se hacen trasparentes al entendimiento, es la ley natural. Pero la podemos interpretar también en el contexto platónico como idealidad; en el aristotélico como forma natural y en el kantiano sencillamente como objetividad. En los tres casos se trata de

[39] Cf. en la Crítica de la razón pura, la segunda sección del tercer Hauptstück, que lleva por título: «Del ideal trascendental, (prototypon transcendentale)». B600, A572 ss.

[40] Quien lo pretenda puede seguir, como he hecho yo, el comentario de este pasaje en la monumental obra de Jean Hyppolite, Génesis y estructura de la Fenomenologia del Espíritu de Hegel, Barcelona: Peninsula, 1974. Pero especialmente la muy desconocida, y por desgracia no traducida al castellano, de Eugen Fink, Hegel, Phänomenologiesche Interpretationen der Phänomenologie des Geistes, Frankfurt a. M.: Klostermann, 1977.

[41] Polo ha estudiado la identidad según Hegel en el c. I de Hegel y el posthegelianismo. Eunsa, Pamplona $1999^{2}$.

THÉMATA. Revista de Filosofía, N50 julio-diciembre (2014) pp.: 69-94

doi: 10.12795/themata.2014.i50.03 
la síntesis entre forma intelectual y diversidad empírica, material o sensible; síntesis en la que, repito, se produce al final el encuentro consigo misma del alma, del intelecto o de la forma pura del Yo. Pues bien, y esto es lo que aquí nos interesa, el medio en el que tiene lugar esa síntesis reflexiva que termina por abarcar toda realidad, es, dice Hegel, «la fuerza».

Hegel hace aquí una muy artificiosa elaboración de este concepto para convertirlo en gozne que articula el orden empírico y sensible con el inteligible y trascendental. Sin darse cuenta que al hacerlo precisamente transforma esa noción de fuerza de modo que la hace muy interesante para entender la idea de inteligibilidad, precisamente en un sentido que trasciende el puro sentido físico de la idea newtoniana de fuerza.

Para Newton (y tras él para todo el naturalismo moderno que al radicalizarse filosóficamente se hace materialismo) la fuerza es el principio responsable de la modificación del movimiento, actuando sobre la masa inerte que pasivamente la recibe, y que a la vez la anula con su reacción. La consecuencia es que una fuerza aparece allí donde se agota, a saber, en la modificación del movimiento de una masa. De este modo la fuerza, igual a la masa por la aceleración, se mide en su «exhaustión». Esto constituye el momento alienante por el que la fuerza tiene que hacerse exterior a sí misma en la efectividad. Pero esta exteriorización efectiva no es suficiente, porque la fuerza se realiza negando la negación que esa exteriorización supone y manteniéndose en sí misma, constituyendo así una interioridad que convierte esa exteriorización en expresión. La fuerza entonces no se agota, antes bien se re-fuerza en su ejercicio, a la vez que en su expresión saca afuera la interioridad así constituida. "Lo que la fuerza expresa -dice Hegel- es que su expresión (Äusserlichkeit) es idéntica con su interioridad» ${ }^{42}$.

Esto es fundamental, por varias razones. En primer lugar porque al representar para todas las cosas un volcarse hacia fuera, cada fuerza despierta el eco de todas las demás, de modo que la fuerza se convierte en interconexión de la totalidad. De tal forma además que en esa mutua solicitación, la interioridad en la que la fuerza se repliega, ya no es la capsula aislada de la mera percepción sensible, sino, por así decir, una interioridad cósmica, que Hegel llama ahora "la ley de la fuerza» y en la que se da paso, al mundo inteligible como interioridad universal primero, y luego al descubrimiento de que esa totalidad natural en la que todo está dinámicamente relacionado es al mismo tiempo

[42] Wissenschaft der Logik, II, Ed. Suhrkamp, 6, p. 179. Cf. También ibid. P. 172: «La fuerza es la unidad negativa en la que se resuelve la contradicción entre el todo y sus partes; es la verdad de esa primera relación. El todo y las partes constituyen la relación sin concepto en la que originalmente decae la imaginación. De forma objetiva se trata del agregado muerto y mecánico, que por un lado tiene una determinación formal (...), que por otro le resulta externa. La relación de la fuerza es, por el contrario, la superior reflexión en la que la unidad del todo, que constituía la relación de la independiente alteridad, deja de ser para esa multiplicidad algo externo e indiferente». (La traducción es mía).

THÉMATA. Revista de Filosofía, ${ }^{\circ} 50$ julio-diciembre (2014) pp.: 69-94 doi: 10.12795/themata.2014.i50.03 
manifestación, expresión de sí misma; y real por tanto sólo en el entendimiento en el que la conciencia que antes era mera percepción sensible, busca elevarse a reconocimiento de sí en la totalidad; busca llegar a ser a la vez, en el mismo acto, el entendimiento y lo entendido. Ese campo universal de fuerzas que se limitan respectivamente termina por ser un espacio lógico; y los focos dinámicos en los que tienen su anclaje, en la medida en que retienen reflexivamente en sí esa respectividad, se convierten en "significaciones».

La genialidad de Hegel consiste aquí en transformar la idea física de fuerza en un concepto a la vez gnoseológico. La physis, o si queremos el noumenon kantiano, ya no es fuerza bruta, un límite opaco que reduce el intelecto a mera experiencia; y menos es ya un "X ignotum». Es más bien, a la vez, un abrirse y resguardarse, una dynamis expresiva, en la que se sintetizan los términos que veíamos como antítesis en la idea aristotélica de inteligibilidad: como un exponerse, por un lado, a la luz universal en el desvelamiento o alétheia, y entonces como forma e idea, que, por otro, íntimamente se guarda en cada individuo como concepto.

Pues bien, esto vuelve a ser un rodeo cuyo último fin no es otro que clarificar la idea aristotélica de intelecto agente. Y vista en el espejo de este desarrollo hegeliano, la teoría del Estagirita adquiere, no ciertamente una nueva significación, pero sí una nueva vivacidad. Porque no nos cuesta nada reconocer en esta idea de "fuerza» la concepción del ser como enérgeia que caracteriza a Aristóteles. En ella vemos el ser no en el contexto del mero cierre categorial predicativo ${ }^{43}$, sino como expansión en la que todo ente se abre a ese campo universal de respectividad dinámica. Y aquí no cabe el solipsismo. No el capsular cartesiano. Pero tampoco la pretensión kantiana de que el conocimiento teórico es una mera construcción objetiva realizada a priori a partir de materiales empíricos carentes en sí mismos de significación. Ser es apertura universal, respectividad dialéctica (de diálogo) en ese espacio en el que todas las cosas igualmente se abren desde su naturaleza propia igualmente dinámica (physein $)^{44}$. Pero la fuerza no se queda en la pura difusión de sí; en la alteridad que esa respectividad impone como condición. Antes bien, mantiene al abrirse la identidad consigo misma. Y entonces, volviendo a la terminología aristotélica, la enérgeia es también entelékheia: lo que termina en sí misma; lo que recoge en sí esa interacción. De dos maneras: primero como expresión de sí misma. Y así, como entelekhéia, la enérgeia no es fuerza bruta, sino que se convierte en forma que determina el modo de existir, que es modo de manifestarse. Las cosas no sólo actúan, interactúan, de modo que en ello se expresan y manifiestan. Y así esas cosas no son un puro hecho,

[43] En el sentido de la verdad como corrección predicativa que Heidegger critica en Platons Lehre von der Wahrheit.

[44] Cf. el escrito de Heidegger ya citado: «Vom Wesen und Begriff der Physis. Aristoteles, Physik, B, 1»

THÉMATA. Revista de Filosofía, Nº50 julio-diciembre (2014) pp.: 69-94

doi: 10.12795/themata.2014.i50.03 
condicionado desde fuera, sino que efectivamente son, a saber, de un modo determinado; son significativas.

En su obsesivo panlogismo, Hegel pretende dejar atrás los limites naturales de este proceso onto-lógico, exigiendo que todo sea absolutamente y sea absolutamente conocido (saber absoluto del Absoluto); exigiendo pues que toda realidad y todo juicio sobre ella forme parte de la vida interna de Dios. Aristóteles no tiene esos problemas. Y entiende que esa trasparencia última en la que todas las cosas buscan la expresión de sí mismas, se da según el más y el menos, en proporción a una entelékheia propia que en cada cosa tiene el límite de la finitud y el inacabamiento. Todo ser es energético, se expresa dinámicamente y se hace significativo de una interioridad onto-lógica. Pero no por igual, sino según el más o el menos de ese propio ser, que está limitado por el lado finito y condicionado de la fuerza que ahora llama Aristóteles propiamente dynamis o "potencia». Pero esa potencialidad o limite energético, lo que sobre todo limita es la capacidad de recoger en la propia reflexión, no ya las significaciones propias (que por supuesto) sino las ajenas. Todo está dinámicamente relacionado con todo, interactúa en el ámbito de la universalidad en el que se expresa según es. Pero no todo es capaz de recoger en sí esa universalidad de modo que se haga expresa en la propia reflexión la reflexión en que cada cosa consiste. Y por ello no todas las cosas son capaces de inteligir, de poner de manifiesto en su experiencia las formas significativas de las demás cosas. No todas las cosas «se enteran» de lo que en ese campo de universal respectividad está implícito como manifestación formal de todo lo demás.

$\mathrm{Y}$ volvemos al intelecto agente, porque ahora podemos decir que no es otra cosa que la enérgeia, la fuerza que en su ejercicio se refuerza e incrementa así su reflexividad original, trasformando en interioridad ese espacio abierto de universal manifestación; de modo que acogiéndolo en sí se hace también manifestación de interioridades ajenas: no sólo expresión, sino concepto. Es así como la enérgeia, superando su finitud se hace quoddamodo omnia, y reproduciéndolas en sí virtual e intencionalmente se convierte en recipiente de las formas y significaciones de todas las cosas.

\section{Ens est illud primum quod cadit in intellectu}

La expresión forma formarum nos viene ya apareciendo en diferentes contextos desde que Aristóteles la usase para caracterizar al intelecto agente. Y el caso es que incluso viene de más atrás, porque también Platón había dicho del Bien que era idea de todas las ideas. Y luego, efectivamente, la hemos usado para referirnos a la apercepción trascendental kantiana, y en cierto sentido también a la idea de fuerza reflexiva en Hegel. Pues bien, la idea de una forma que trascendiendo todas las formas expresa el 
núcleo, no divisivo sino comúnmente participado, de cada una de ellas, es lo que ahora determina la idea filosófica de «trascendentalidad» ${ }^{45}$.

No son pocos los intérpretes que adscriben este adjetivo «trascendental» a la forma kantiana del idealismo. Caracteriza así a las formas subjetivas de la síntesis objetiva de la experiencia, por contraposición a unas supuestas formas "trascendentes» que determinasen "en sí» a los objetos de dicha experiencia. Pero sin ser incorrecta, esta interpretación, si se quiere estrictamente literal, deja de lado algo mucho más fundamental, a saber, la esencial dinámica reflexiva que acompaña a todas las formas de representación sin agotarse en ninguna de ellas. De modo que este adjetivo corresponde esencialmente al Yo, como forma reflexiva que efectivamente hace de las modificaciones sensibles de la experiencia representaciones a la vez de las cosas conocidas y del mismo Yo que, como forma formarum, en cada caso las "trasciende».

Por otra parte, de forma que muchos son incapaces de relacionar con la anterior, nos encontramos ahora con el uso de este adjetivo al referirnos a lo que Tomás de Aquino llama ahora ipsum esse, al ser que determina a las cosas a ser, no esto o aquello; al ser que no está en cuanto tal ulteriormente determinado por una forma restrictiva de ser, sino que determina al ente como lo que es en absoluto, más allá de toda forma categorial, es decir, trascendentalmente. Y de él dice el de Aquino que es «actualitas omnium actuum et etiam ipsarum formarum ${ }^{46}$, es pues, primum formale in omnibus ${ }^{47}$, y perfectio omnium perfectionum ${ }^{48}$.

Este carácter trascendental del ser ya lo había definido Aristóteles, diciendo que no es un género ${ }^{49}$, sino que se dice de múltiples modos de cosas diversas. Pero al mismo tiempo, no es algo que se disperse en la pluralidad de su significación, sino que a la vez se mantiene idéntico efectivamente como un ipsum, como lo que es por sí y no por otro. Podemos por tanto concluir que lo que Tomás de Aquino denomina ipsum esse no está lejos de lo que Hegel llama "fuerza», de modo que se muestra esencialmente como perfectio o entelékheia, o lo que es lo mismo, como reflexión, que se dice de un sujeto al que le compete ser por sí mismo, o sea, subsistir. El ser se dice, pues, de algo que mantiene

[45] L. Polo plantea el conocimiento en términos de unidad en las cuatro primeras lecciones de sus Lecciones de psicología clásica. Eunsa, Pamplona 2009.

[46] De Pot., q. 7, a. 2, ad 9: «Esse est inter omnia perfectissimum, quod ex hoc patet, quia actus est semper perfectior potentia. Quaelibet autem forma signata non intelligitur in actu nisi per hoc quod esse ponitur (...). Unde patet quod hoc quod dico "esse" est actualitas omnium actuum et propter hoc est perfectio omnium perfectionum (...). Unde non sic determinatur esse per aliud sicut potentia per actum, sed magis, sicut actus per potentiam».

[47] Cf. Santo Tomás, In II Sent., a 1, q 1, a l: «Plura sunt prima principia, ut materiale primum quod est materia prima, et primum formale, quod est esse»

[48] De Potentia, ibídem.

[49] Met, III, 3, 998 b 16 ss.

THÉMATA. Revista de Filosofía, Nº50 julio-diciembre (2014) pp.: 69-94

doi: 10.12795/themata.2014.i50.03 
reflexivamente su identidad en la pluralidad de sus manifestaciones. Eso es la substancia o naturaleza, de la que, en efecto, la pluralidad de interacciones en un mundo plural se hace significativa. Por eso, el ser que se dice de algo requiere algo dicho; o lo que es lo mismo, se articula en una estructura predicativa; en un ti kata tinós, como lo expresa Aristóteles ${ }^{50}$. O lo que es lo mismo: el ser significa, es inteligible, manifiesta la realidad de lo que es, reclama por así decir entendimiento, y es en sí y por sí verdadero. No, como dice Heidegger, en el sentido de la corrección predicativa, sino precisamente como un aléthein, como desvelamiento de la cosa en el espacio significativo al que se abre su fuerza, su dinámica energética.

En ese espacio abierto, determinadas substancias en virtud de la intensidad reflexiva de su propia actividad, son capaces de situarse, precisamente trascendiendo la forma restrictiva de esas significaciones. Aquí sí lo dice bien Heidegger: trascendiendo todo ente, abriendo por detrás y por encima de cada uno de ellos un horizonte de totalidad cósmica, situándose como ser-en-el-mundo, hay un existente que en su actividad se entiende a sí mismo en ese espacio abierto en el que para todas las cosas se hace manifiesto, no el modo concreto de su facticidad, sino el hecho radical en el que esa facticidad se hace para ellas expresión de su fuerza interna; y en el que, por encima del modo relativo de su respectividad, esas cosas fundamentalmente son. Sólo desde ese horizonte de universalidad las cosas se hacen significativas y piden "ser dichas», que se haga explícita su significación y las «entendamos». Y eso es lo que significa que el ente es «id quod primo cadit in conceptione intellectus» ${ }^{51}$; o que el ser es de nuevo forma formarum, la forma de toda intelección.

Por razones que nos llevarían aquí muy lejos, todo el empeño de Heidegger, al menos en su filosofía posterior a la así llamada Kehre, consiste en impedir que ese espacio abierto en el que las cosas se hacen manifiestas se cierre reflexivamente en una posición subjetiva. El Da-sein, el ex-sistente que se sitúa en el infinito abierto de la mundanidad (del Ser), debe renunciar a reapropiarse en él de su mismidad originalmente perdida, a la espera del Ereignis, de una espontaneidad temporal que de forma incontrolable se abre en la presencia y que radicalmente nos supera ${ }^{52}$. El esse deja ser, renunciando él mismo a ser un ipsum. De este modo, el segundo Heidegger quiere ceder al tiempo el

[50] De anima, III, 6, 430 b 26.

[51] De veritate, q 21, a 1.

[52] Cf. Por ejemplo Einführung in die Metaphysik, Tübingen 1953, p. 108: «Pensar (Vernehmung) es lo que dice el principio de Parménides (identidad con el ser) y no una facultad del hombre ya determinado. Más bien es el pensar un suceso en el que sólo sucediendo entra el hombre como el que es en la historia, como el que aparece; esto es, llega él mismo al ser. Pensar no es una forma de administrar que fuese propiedad del hombre, sino que, al revés, el pensar es el acontecer que al hombre posee (...). Lo que en este principio de Parménides se cumple es, ni más ni menos, la consciente emergencia del hombre como el histórico». (La traducción es mía.)

THÉMATA. Revista de Filosofía, $\mathrm{N}^{\circ} 50$ julio-diciembre (2014) pp.: 69-94 doi: 10.12795/themata.2014.i50.03 
protagonismo ontológico, constitutivo del mismo ser; protagonismo al que la subjetividad debe renunciar para no malinterpretarlo en una onto-teo-logía o metafísica.

Dejémoslo ahí. Son opciones fundamentales. Y tiene razón Fichte -cuya intención última es justo lo que aquí está en juego- en que el tipo de filosofía que se tiene depende del tipo de hombre que se es. Toda la ontología clásica representa la denodada lucha de la mismidad contra el tiempo; lucha en la que el post-nietzscheano Heidegger decide rendirse. En contra también de su primer intento en Ser y tiempo, en el que, siguiendo casi a la letra al mismo Fichte, Heidegger reconoce que lo que abre el horizonte trascendente de la mundanidad (en el que ocurre que las cosas son), es la pasión del Dasein, del ex-sistente, por recuperar sus mismidad perdida en la dispersión finita, circunstancial, de dicha mismidad.

Por el contrario, sostengo aquí que el ser, tampoco eso que Heidegger llama das Seiende im ganzen, no representa un catálogo inconexo de acontecimientos, una universal respectividad interactiva sin otro sentido que su mera facticidad. Lo podemos decir de otro modo: el ipsum no sólo acompaña sino que de algún modo precede al esse, quizás también en el mismo sentido en que la enérgeia es al mismo tiempo lo que se cierra reflexivamente en sí misma como perfección o entelékheia. Ser es ser sí mismo, hypokeimenon, substantia. Lo que quiere decir que el ser constituye más bien un universo significativo.

De este modo, esa apertura universal, ese espacio en el que el alma se hace quodammodo omnia y en ella (tendencialmente) todas las cosas inteligibles; eso que Aristóteles llama intelecto posible; ese ámbito de universalidad en el que desde su significatividad podemos decir lo que las cosas son, requiere una actividad más básica, primera, originalmente reflexiva, so pena que el sujeto se pierda en la pluralidad de su experiencia, no se entere, y las cosas se queden sin ser dichas. Hace falta una intelección original que en todos sus actos se entienda a sí misma. Hace falta que el esse sea, como un ipsum, él mismo subsistens ${ }^{53}$. Hace falta, pues, que antes de cualquier "Yo pienso", a saber, "esto o aquello", supongamos un "Yo pienso en absoluto» que como forma activa acompañe toda representación. Sólo que ese "Yo pienso» es más bien un "Yo soy». Fichte y el Éxodo (Yahvé es "Yo soy») son los que al final tienen razón. Pero ese Yo, que radicalmente es, ya no tiene ante sí meras representaciones, más o menos objetivadas, sino más bien aquello que igualmente por sí mismo es. Y entonces entender es comprender, y tiene lugar en eso que Kant después como expresión de la pura buena voluntad llamara «reino de los fines», de las entelekheiai; reino en el que el sujeto se reconoce a sí mismo, no en las cosas, sino en otros sujetos, que también se expresan, de modo que entenderlos no es entonces construirlos a priori, objetivarlos, sino,

[53] Cf. Sto. Tomás, CG, IV, 11: «Deus enim verus subsistens est: cum maxime sit per se ens».

THÉMATA. Revista de Filosofía, Nº50 julio-diciembre (2014) pp.: 69-94

doi: 10.12795/themata.2014.i50.03 
atendiendo a su manifestación, dejarlos ser lo que ellos por sí mismos son y quieren ser. Por eso es el intelecto en su carácter agente, lo mismo que el ser, esencial expresión de libertad, como aquello capaz de reconocer libertades.

Y tiene que ver con esto que Platón dijese que la última forma de todas las formas es el Bien; y que todo conocimiento sigue, al recordar, la vía del eros, la misma por la que todas las cosas, más que ser, aspiran a ser lo que son; y por la que el entendimiento también aspira a redimir a los fantasmas (phainomena) de su materialidad empírica, para alcanzar en la reflexión la substancia (noumena) que quieren ser. En esta fusión de intelecto agente aristotélico y buena voluntad kantiana, el pensamiento dejaría de ser filo-sofía para convertirse en contemplación teórica; el ideal kantiano de la razón pura se vería entonces realizado; se sanaría también la escisión entre ciencia y razón práctica; y podríamos vislumbrar lo que significa que, en el principio en el que existía el Verbo, la idea de todas las cosas, Dios sigue siendo esencialmente Amor. En el nombre del Padre, del Hijo y del Espíritu Santo. Pero esto queda para otro intento, en el que procuremos aclarar tantas cosas que aquí quedan confusas. 